\title{
Redes masónicas epistolares entre Marruecos, México y Cuba durante la segunda República española
}

\author{
Masonic and Epistolary networks between Morocco, Mexico and \\ Cuba during the Second Spanish Republic
}

\author{
Valeria Aguiar Bobet \\ Universidad Jaume I de Castellón, España \\ vaguiar@uji.es
}

Recepción: 14 de febrero de 2018/Aceptación: 2 de mayo de 2018.

doi: https://doi.org/10.15517/rehmlac.v10i1.32432

Palabras clave

Protectorado español de Marruecos; segunda República española; relaciones internacionales; redes sociales; colonialismo.

Keywords

Spanish Protectorate of Morocco; Second Spanish Republic; International Relations; Social Networks; Colonialism.

Resumen

Durante la segunda república española, los contactos de las logias españolas del Norte de África y algunos talleres de América Latina fueron constantes. El intercambio epistolar adquirió cifras destacables con logias pertenecientes a la Gran Logia Oriental Peninsular de Yucatán, la Gran Logia "Unida Mexicana" de Veracruz o La Gran Logia de la Isla de Cuba. Dentro del marco geográfico del protectorado español de Marruecos y plazas de soberanía, destacan talleres como Perseverancia no. 70 de Larache o Hércules no. 55 de Ceuta, ambos auspiciados por la Gran Logia Española, así como algunos contactos con la Gran Logia Regional de Marruecos, perteneciente al Gran Oriente Español. Este trabajo nos aproxima a la relevancia y particularidad de estos vínculos, al establecimiento de una red internacional (transoceánica y transcontinental) de solidaridades y colaboración masónica, cuya intensidad superaba las relaciones de talleres europeos, en particular a la de la Península Ibérica.

Abstract

During the Spanish Second Republic, communications between the Spanish lodges of North Africa and some lodges of Latin America were constant. Epistolary exchanges were notable especially with the Grand Lodge "Eastern Peninsula" of the State of Yucatán, the Grand Lodge "United Mexico" of Veracruz or the Grand Lodge of Cuba Island. In the Spanish Protectorate of Morocco and sovereign territories, lodges such as Perseverancia no. 70 of Larache or Hercules no. 55 of Ceuta are notable in this labor, both sponsored by the Spanish Grand Lodge. These also had some considerable contacts with the Grand Regional Lodge of Morocco, that belonged to the Spanish Grand Orient. In this paper, we will try to outline the relevance and characteristics of these links and the origins of an international (transoceanic and transcontinental) solidarity network of cooperation, more intense than with other European lodges, particularly those of the Iberian Peninsula. 
Los contactos epistolares entre las logias españolas del Norte de África y algunos talleres de América Latina fueron constantes y frecuentes durante la II República, produciendo y consolidando verdaderos lazos fraternales entre ambos lados del Atlántico. Las líneas que siguen constituyen un ensayo histórico que trata de aproximarse a la relevancia y particularidad de estos vínculos y ahondar en el establecimiento de una red internacional, transoceánica y transcontinental de solidaridades y colaboración masónica que superaba en intensidad las relaciones de los talleres magrebíes con otros geográficamente más próximos. Para ello, se abordarán diferentes disposiciones al respecto del análisis de redes masónicas internacionales, además de presentar y valorar los resultados cualitativos y cuantitativos de los datos obtenidos a partir de las fuentes documentales utilizadas. Debemos puntualizar, sin embargo, dado el encuadre de esta comunicación dentro de un proyecto más amplio sobre la masonería española en Marruecos y la carencia de material documental consultado al respecto de las logias americanas, que serán los talleres españoles del Norte de África los actores principales de estos vínculos. Serán los que, por su propia trayectoria histórico-política -el contexto republicano español y colonial en Marruecos- marquen el transcurso, la intensidad y la relevancia de las relaciones con la masonería latinoamericana.

\section{Relaciones internacionales masónicas y perspectivas de análisis}

Sin distinción, las obediencias y logias masónicas establecen de forma continua y constante relaciones formales con otros talleres locales, regionales e internacionales. Estas relaciones les otorgan reconocimiento y legitimidad externa además de crear lazos fraternales, ideológicos y todo tipo de interconexiones y comunicaciones. La propia organización piramidal de la orden favorece el desarrollo de este ensamblaje por medio de las figuras de los visitadores, así como el obligado mantenimiento de la correspondencia y la circulación de boletines, revistas o trabajos, cuyo tráfico produce multitud de redes, redes donde fluctúan personas, pero, sobre todo, ideas, ideologías, tendencias. Estas redes, además, se construyen a partir de una serie de criterios y características: según el territorio, las diplomacias y la política, en sentido general, de la propia obediencia o la logia en cuestión y se manifiestan en diferentes procedimientos: planchas, viajes, visitas y garantes de amistad. Entre ellos, la correspondencia epistolar es la fuente documental principal para revelar todo este tipo de interacciones entre diferentes talleres más allá de las formalidades propias de los garantes y a pesar de las vinculaciones directas con motivo de viajes y los visitadores. Las cartas informan de relaciones efectivas, vínculos nominales, contenidos y atributos, del mismo modo que muestran su funcionalidad operativa real y revelan la globalidad de sus dimensiones. Y a su vez, la secuencia cronológica que abarcan, muestra la evolución de las relaciones, sus regularidades y variaciones, su renovación y durabilidad, 
así como la duración de las redes en relación con la propia historia de los actores, de las logias y de sus contextos ${ }^{1}$.

El análisis de la correspondencia, en este sentido, se muestra esencial a la hora de establecer las valoraciones y magnitud de la red o las redes establecidas, por lo que, para abordar el conjunto que nos ocupa, hemos tomado como punto de partida diferentes ítems propuestos por otros autores ${ }^{2}$ :

- Logias americanas o norteafricanas que inician relaciones francmasónicas.

- Inicio, desarrollo, contextualización y fin de dichas relaciones: intereses, motivos, el tema de América en el Norte de África, el tema marroquí o el protectorado español en las logias americanas, etcétera

- Aspectos formales de las logias: obediencia, localización geográfica, posibles vínculos establecidos con anterioridad.

- Vínculos migratorios: inmigrantes americanos iniciados en América y afiliados en Marruecos y, viceversa, españoles o marroquíes iniciados en Marruecos, que emigran a América y se afilian a logias americanas.

- Tipología y contenido de las relaciones: garantes de amistad, cuadros lógicos, intercambio de folletos, revistas, trabajos, colaboración.

- Frecuencia, densidad y durabilidad de las relaciones. Años de mayor contacto.

No obstante, este enfoque exige también un encuadre global de relaciones francmasónicas que muestre el mapa geocultural y geopolítico de los vínculos, insertándolos así en las redes masónicas internacionales. Este aspecto es imprescindible si tenemos en cuenta que las relaciones y todas las redes, en general, están insertas dentro de un marco más amplio, global, que si bien autores como Dévrig Mollés han denominado sistema-mundo masónico ${ }^{3}$,-partiendo de la conceptualización del sistema-mundo moderno

\footnotetext{
${ }^{1}$ José María Imízcoz Beunza y Lara Arroyo Ruiz, "Redes sociales y correspondencia epistolar. Del análisis cualitativo de las relaciones personales a la reconstrucción de redes egocentradas", REDES 21, no. 2 (diciembre 2011): 98-138, http://revistes.uab.cat/redes/article/view/419

${ }^{2}$ Yván Pozuelo, "Las relaciones masónicas entre Asturias e Hispanoamérica en los siglos XIX y XX. Estado de la cuestión", REHMLAC 1, no. 1 (mayo-noviembre 2009): 262-281, https://revistas.ucr.ac.cr/index.php/rehmlac/article/view/6867/6554. También, Manuel de Paz Sánchez, La masonería y la pérdida de las colonias (Santa Cruz de Tenerife: Idea, 2006): 91-151.

3 Véanse diferentes artículos de Dévrig Mollés, por ejemplo: "Triangle atlàntiques et triangle latin: l'Amérique latine et le système-monde maçonnique (1717-1921)", REHMLAC 1, no. 5 (mayo-noviembre 2013): 188-196, https://revistas.ucr.ac.cr/index.php/rehmlac/article/view/10367/9754; "Le système-monde maconnique à la veille de la Première Guerre mondiale: une analyse archéologique", REHMLAC 6, no. 2 (diciembre 2014-abril 2015): 12-32, https://revistas.ucr.ac.cr/index.php/rehmlac/article/view/18196/22736; "Le "Triangle atlantique": émergence et expansion de la sphère maçonnique internationale", Nuevo Mundo Mundos Nuevos (noviembre 2014), https://nuevomundo.revues.org/67498?lang=es\#text; "L' histoire globale et la question maçonnique: éléments pour une analyse", REHMLAC 6, no. 1 (mayo-diciembre 2014): 1-32, http://revistas.ucr.ac.cr/index.php/REHMLAC/article/view/15225
} 
defendido por I. Wallerstein-, se configura, más bien, dentro de la cosmovisión contemporánea que comienza a discurrir y ordenar, precisamente, una red de interrelaciones globales, es decir, que se inserta en el proceso tan afanado en la actualidad como controvertido, conocido como globalización ${ }^{4}$. En esta cosmovisión, los ideales y preceptos masónicos, tales como la fraternidad, la igualdad entre pueblos, razas y naciones, la solidaridad internacional, etcétera, producen los mecanismos de solidaridad y sociabilidad precisos para establecer diferentes redes e interconexiones con distintos contenidos y significantes. Pero, más que eso, produce la interconectividad del mundo a partir de preceptos comunes, de la comprensión del mundo no solo en su concepción global, sino según unos mismos parámetros que coinciden desde lo local y particular hasta lo internacional y general. $\mathrm{Y}$ todo ello en un contexto incentivado por las conexiones entre actores o asociaciones en las cuales convergen múltiples naciones, instituciones y sujetos con intereses, ideologías y objetos comunes. Así, los individuos o logias pueden ser tomados como actores de una historia global en la medida en que, a través de sus acciones y relaciones se percibe la articulación social entre sectores de actividad, espacios o esferas. Y, además, pueden entenderse como parte de un ensamblaje mayor, nunca individualmente o de forma segmentada, por lo que los resultados son siempre indicadores de tendencias, más que estadísticas y datos cuantitativos incuestionables.

En este sentido, las redes que nos ocupan se integrarían, por un lado, dentro del contexto europeo de la colonización africana, en la que la mayor parte de las masonerías de este continente pertenecieron, en el primer trienio del siglo XX, a diferentes obediencias extraterritoriales, sobre todo a la anglosajona, la española y la francesa. Y por otro, a las diferentes realidades de los países latinoamericanos, ya independizados, con regímenes republicanos y en un creciente proceso de desarrollo económico. De hecho, en el territorio marroquí que protagoniza estos vínculos, dividido desde 1912 por las dos potencias coloniales que la ocuparon, Francia y España, coexistirán logias de los tres países mencionados desde finales del siglo XIX.

Junto a ello, la llegada de la II República española, instaurada en 1931, supondría para España y sus territorios africanos un nuevo sistema político con sus derivados aspectos económicos, socio-culturales e ideológicos, muy cercanos a los preceptos expuestos por la masonería universal y la española, que no solo incentivaría la creación y el fortalecimiento de diferentes logias por todo el territorio nacional, sino también en la zona colonial. Fervor que afectaría, a su vez, al auge de las relaciones exteriores de la masonería española con las logias y obediencias latinoamericanas, precisamente por la aproximación ideológicaademás de la histórica y cultural ya existente -entre el nuevo régimen y aquellos

\footnotetext{
${ }^{4}$ Véase Jessica Harland-Jacobs, "Fraternidad global: masonería, imperios y globalización”, en 300 años: Masonerías y masones. Tomo V. Cosmopolitismo, eds. Ricardo Martínez Esquivel, Yván Pozuelo y Rogelio Aragón, (México: Palabra de Clío, 2018), 65-93.
} 
implantados en los diferentes países latinos ${ }^{5}$. No es extraño, por tanto, que estos vínculos se mantuvieran y continuaran en el protectorado magrebí. Es más, las relaciones establecidas en los siglos XIX y XX por los militares que prestaron sus servicios en las Antillas o en Filipinas pueden explicar las especiales connotaciones de estos lazos tricontinentales, sobre todo porque estos mismos militares participaron en la pacificación del nuevo territorio colonial africano y, a su vez, levantaron o nutrieron las logias marroquíes ${ }^{6}$.

En definitiva, en las páginas que siguen se cuantificará y calificará la red transoceánica y transcontinental configurada por las logias norteafricanas y otras allende el Océano Atlántico con el fin, no solo de determinar las características y la tipología de los vínculos, así como aquellas particularidades que unían ambos lados, sino con la finalidad de demostrar que la masonería es uno de los objetos de estudio más adecuados para comprender y definir el desarrollo histórico de la globalización. Es decir, para conocer y considerar aquellos elementos y particularidades que influyeron en el desarrollo de una incipiente visión del mundo como un todo globalizado, en los que una institución cosmopolita, universal y occidental como es la masonería, contribuyó y participó. Así, bajo los mismos preceptos ideológicos, diferentes actores desde Marruecos hasta América, coordinaron sus acciones, intercambiaron ideas y, sobre todo, compartieron la misma forma de entender el mundo y el contexto en el que vivieron.

\section{La red de relaciones masónicas norteafricana y latinoamericana}

Los contactos que se han registrado en el espacio y tiempo que nos ocupa, abarcan las plazas de soberanía Ceuta y Melilla con sus correspondientes logias: Hércules no. 55 de la GLE y Hércules no. 446 del GOE en la primera plaza, 14 de Abril no. 450 del GOE en la zona melillense, y las ciudades de Tetuán, Larache, Alcazarquivir, Xauen, Villa Alhucemas, con especial mención de Perseverancia no. 70 de la GLE de Larache y la GLRM jurisdiccionada por el GOE y cuya sede se encontraba en Tetuán. Se han incluido las plazas de Ceuta y Melilla por su situación norteafricana y las continuas relaciones con los talleres del protectorado. Aunque pertenecieron a una obediencia regional diferente, la Gran Logia Regional del Mediodía de España (GLRME), formaban parte del mismo entramado socioeconómico y cultural que las interrelacionaba en el mundo profano y

\footnotetext{
${ }^{5}$ En el Boletín de la GLE, junio 1931, 5-6, noviembre-diciembre 1931, página 7 aparecen las felicitaciones de varios altos organismos latinoamericanos. Véase Pozuelo, "Relaciones y opiniones oficiales de las masonerías españolas sobre Iberoamérica durante la II República (1931-1935)", REHMLAC, 2, no. 2 (diciembre 2010abril 2011): 134-135, http://revistas.ucr.ac.cr/index.php/REHMLAC/article/view/6600

${ }^{6}$ De Paz Sánchez, La masonería y la pérdida de las colonias, 273-299; Vicente Moga Romero y Adoración Perpén Rueda, "Orígenes ideológicos de los talleres masónicos contemporáneos en Melilla: Militares y masonería (1983-1927)", en Masonería, revolución y reacción, coord. José Antonio Ferrer Benimeli (Alicante: CEHME, 1990): 717-741.
} 
masónico, produciendo unas relaciones constantes, bidireccionales y horizontales ${ }^{7}$. Además, en la documentación consultada, las logias latinoamericanas no diferenciaban estas ciudades de las restantes del territorio marroquí, haciendo siempre alusión a Marruecos como situación geográfica y a España como eje político y soberano del territorio colonial. No incluimos en este baremo las logias españolas situadas en la zona de influencia francesa o tangerina por ser, ambas, realidades diferenciales ${ }^{8}$.

No obstante, antes de analizar exclusivamente la correspondencia y las redes establecidas a partir de ellas, ahondaremos primero en los contactos directos entre ambos lados del Atlántico, así como la presencia de América o el tema americano en las logias magrebíes.

\section{América en las logias españolas norteafricanas}

El tema americano o América, es una constante en las tenidas semanales en los trabajos de las logias españolas del Norte de África: la igualdad de razas en este continente, la consideración de España como la "madre patria" de los países latinoamericanos", la independencia de los mismos, la estabilidad de sus repúblicas o de la propia masonería:

Se identifican episodios históricos en la época en que nació vuestro templo (...). México, libre de la oprobiosa intervención del imperialismo francés, redimido por el torrente de sangre que vertieron sus hijos abnegados, despierta con el BENEMÉRITO JUÁREZ ${ }^{10}$ y avanza con paso seguro por el camino de la verdad, liberado y digno ${ }^{11}$.

Los nombres simbólicos con esta temática, por ejemplo, "América", "Américo", "Plutarco Elías Calles", "México", "Argentina"12, responden de igual modo a este vínculo cultural e ideológico, especialmente por la importancia otorgada a los procesos independentistas y los regímenes republicanos. Moga Romero en su monografía sobre la

\footnotetext{
${ }^{7}$ Vicente Moga Romero ya ha tratado el tema sobre Melilla y su relación con las logias del protectorado en $\mathrm{Al}$ oriente de áfrica, vol. 2 (Melilla: UNED-Centro Asociado de Melilla, 2005), 442-457.

${ }^{8}$ La zona francesa presenta estatutos diferentes a la española y Tánger era zona internacional. Véase por ejemplo Bernabé García López, "Los españoles en Tánger”, AWRAQ 5-6 (2012): 1-45.

${ }^{9}$ Destaca el trabajo de Ramiro Farpón Pumariega leído para la logia Atlántida no. 448 el 24 de septiembre de 1932. En él analiza la libertad de los pueblos y la relación de la masonería con la independencia de muchos de ellos, además, critica la desigualdad ante la ley en Norteamérica, sobre todo al respecto de la "raza negra". Centro Documental de la Memoria Histórica (CDMH), SE Masonería A. Leg. 115 Exp. 11.

${ }^{10}$ En mayúsculas en el original.

${ }^{11}$ Trabajo de Edmundo Seco de Cabo Quilates no. 11 para Esperanza no. 2 de Veracruz por su 65 aniversario, de marzo de 1934. CDMH SE Masonería A, Leg. 198 Exp. 9.

${ }^{12}$ Blanca Alonso López de Perseverancia no. 70 tenía el nombre simbólico de "América"; José Berenguer Cañadas de Atlántida no. 448 el de "Américo"; Samuel Bentolila también de Atlántida, el de "Argentina", Isaac Edery Edery de Luz no. 449 el de "México"; Amram Cohen Cohen de Atlántida no. 448, el de "Plutarco Elías Calles", personaje revolucionario mexicano, entre otros. Este último presentó para Tetuán no. 64 un trabajo sobre su pseudónimo, el 24-10-1929. Por orden, CDMH, SE Masonería A, Leg. 83 Exp. 6; Leg. 4 Exp. 10, Leg. 30 Exp. 13; Leg. 195 Exp. 13 y Leg. 83 Exp. 6.
} 
masonería en Melilla, incluye al respecto la consideración de un masón melillense Luis Durán Canosa, puntualizando que en dicha plaza se sentía el "Latir de las Repúblicas americanas"13. En la revista Destellos ${ }^{14}$ de la logia Perseverancia no. 70 de Larache, disponemos, a su vez, de numerosas publicaciones con esta misma temática ${ }^{15}$, siempre con el objeto de que las situaciones que se analizan o las figuras que se comentan sean un ejemplo para España y su masonería ${ }^{16}$. En una ocasión, este diario publicó un número dedicado al "Día de la Raza"17 con motivo del 12 de octubre de 1933, que contenía varios artículos remarcando la reciprocidad de la influencia hispano-americana, primero, al llegar los españoles a América en 1492 "engendrando el ansia de emancipación que les llevó a la libertad"18 y, la segunda, porque "pasan cuatro siglos, poco más, y la luz que irradia al continente americano, llega a la vieja España cuando quiere despertar de un letargo de siglos, que la incomprensión tradicional se empeña en prolongar". ${ }^{19}$ Más representativo es que en el mismo ejemplar de la revista, en un artículo titulado Solo la Fraternidad une a los Hombres y a los Pueblos, se interrelacione la conquista de América con la labor desarrollada en África por el Estado Español, relación, en este caso, que da un giro copernicano en el discurso referente al modelo colonial ${ }^{20}$ :

Y a esa obra de aproximación hispano americana, unida a la que España realiza en África junto al pueblo marroquí, pueblo este que también lleva nuestra sangre, será

\footnotetext{
${ }^{13}$ Libro de actas de la cámara de primer grado de 14 de Abril no. 450. Acta 9 de abril de 1936. SE Masonería A. Leg. 429 Exp. 2 en Moga Romero, Al oriente de África, (2005), vol. 1, 460. También, como indica Yván Pozuelo "la masonería española de la II República seguía preocupándose por cómo se tenía que abordar y contar la historia de la Independencia Iberoamericana en relación con sus preceptos universales, las actuaciones de los masones de España y el espacio latinoamericano del periodo independentista". Pozuelo Andrés, "Las relaciones masónicas entre Asturias e Hispanoamérica", 128.

${ }^{14}$ Impresa por la tipografía "La Ibérica" de B. Pajares, venerable maestro de Perseverancia no. 70. La revista publica su primer número en diciembre de 1932. El último será en 1934.

15 “¡Gran nación Méjico! Primeramente porque no se rige por la siguiente fórmula: gobierno/concordia = clericalismo.”, Destellos (diciembre, 1932): 3

16 "Miren el ejemplo de Cuba. Dejen de pensar en aplastamientos recíprocos y decídanse a servir a España con los postulados inmortales de la libertad", Firmado por Ángel Ossorio. "El ejemplo de Cuba" en Destellos (enero, 1934): 6.

${ }^{17}$ Destellos, Sexta Hoja, (enero, 1933).

${ }^{18}$ Giralda, “Ayer y Hoy”, Destellos, Sexta Hoja (enero, 1933).

${ }^{19}$ Giralda, “Ayer y Hoy”, Destellos, Sexta Hoja (enero, 1933).

${ }^{20}$ Varias podrían ser las reflexiones sobre estos discursos en relación a una especie de modelo colonial español ideal para América y África, que si no se muestra explícita, sí se aprecia de forma subyacente en las apreciaciones, temáticas y lenguajes, en general, de estas relaciones. La masonería en Marruecos disponía y proyectaba un discurso colonial concreto, perfectamente estructurado y coherente para los masones de estas logias, que poco se relacionaba con la visión que se tenía al respecto de la actuación en el continente americano desarrollada siglos atrás o respecto a las pérdidas de sus últimas posesiones de Ultramar. Al respecto, véase de Paz Sánchez, "España, Cuba y Marruecos: masonería, identidades y construcción nacional", Anuario de Estudio Atlánticos 55 (2009): 273-310; y Valeria Aguiar Bobet, "La cultura de la tolerancia en el Marruecos de la II República: el VIII Centenario de Maimónides", en La masonería hispanolusa y americana, De los Absolutismos a las Democracias (1815-2015), eds. José Miguel Delgado Idarreta y Pozuelo (Zaragoza: CEHME, Universidad de Zaragoza y Universidad de Oviedo, 2017), Tomo I, 493-505.
} 
sin duda la obra que más libre del remordimiento de culpas pasadas, hijas de la intolerancia religiosa de hace cinco siglos y que, perdurando hasta hace poco, pretenden algunos mantener aún. [sic] El día que España se una de manera efectiva, sin reservas mentales, a los pueblos de la América hispana y al pueblo marroquí, será la apoteosis del Gran Día de la Fiesta de la Raza ${ }^{21}$.

\section{Migraciones, viajes y contactos directos}

Por otro lado, la migración o los traslados temporales al continente americano ya fuese por trabajo, ocio o por inmigración fueron ocasionales, a diferencia de lo que ocurre con otras logias peninsulares, por ejemplo, las asturianas ${ }^{22}$. Sin embargo, Moga Romero destaca para el caso de Melilla la existencia de una comunidad judía importante con raíces en Venezuela ${ }^{23}$. También, algunos miembros de las logias de la Gran Logia Regional de Marruecos (GLRM), muchos de ellos judíos, proceden de Argentina ${ }^{24}$, Filipinas ${ }^{25}$, Brasil ${ }^{26}$ y Venezuela ${ }^{27}$, fueron iniciados o pertenecieron a logias americanas antes de solicitar ingreso en las marroquíes. Samuel M. Nahón ${ }^{28}$ fue miembro de Harmonía y Fraternidad de Brasil antes de ingresar en Tetuán no. 64 y Emilio Zapico Zarraluque ${ }^{29}$, Delegado General de la Alta Comisaría en Marruecos, fue miembro de la logia Constitucionalista de México antes de pertenecer a Oriente no. 451 de Tetuán. Varios, incluso, vivieron una temporada o regresan por razones de trabajo, familiares o, simplemente, emigran por tales motivos. Por ejemplo, Moisés Lévy Ephraim estuvo trabajando en Argentina de 1910 a 1919 en su puesto de la Alianza Israelita Universal ${ }^{30}$; Leon Cohen Sedero, iniciado en Brasil y uno de los fundadores de la masonería de Tetuán, pide su plancha de quite por su traslado a Buenos Aires debido a la falta de recursos ${ }^{31}$; Isaac Benchaya solicita también su plancha de quite por traslado a Argentina donde se encuentra su hijo ${ }^{32}$. Igualmente, Emilio Zapico, nombrado más arriba, regresa a América, en este caso, porque le destinan a Puerto Rico

\footnotetext{
${ }^{21}$ Luis Hidalgo, "Solo la Fraternidad une a los hombres", Destellos, Sexta Hoja (enero, 1933): 2.

${ }^{22}$ Pozuelo Andrés, "Las relaciones masónicas entre Asturias e Hispanoamérica", 262-281.

${ }^{23}$ Moga Romero, Al oriente de África, 461-462.

${ }^{24}$ Francisco Sánchez Molinillo de Hércules no. 55, procede de Buenos Aires. CDMH, SE Masonería A, Leg 197 Exp. 16.

${ }^{25}$ Manuel Reyes González y su hermano, José Antonio Reyes González, pertenecientes a Lixus no. 446B, son naturales de Manila. CDMH, SE Masonería A, Leg. 154 Exp. 20 y Leg. 186 Exp. 20, respectivamente.

${ }^{26}$ Antonio Guerra Ruiz de Cabo Quilates no. 11, natural de Río de Janeiro. CDMH, SE Masonería A, Leg 12 Exp. 13.

27 Salomón Zrihen Benchimol, miembro de 14 de Abril no. 450, procede de Caracas. CDMH, SE Masonería A, Leg. 204 Exp. 29.

${ }^{28} \mathrm{CDMH}, \mathrm{SE}$ Masonería A, Leg. 31 Exp. 13.

${ }^{29}$ CDMH, SE Masonería A, Leg. 94 Exp. 1.

${ }^{30}$ CDMH, SE Masonería A, Leg. 95 Exp. 5.

${ }^{31}$ Libro de actas de Atlántida no. 448 de 13 de marzo de 1933. CDMH, SE Masonería A, Leg. 404 Exp. 1 y expediente personal Leg. 34 Exp. 25.

${ }^{32}$ Libro de actas de Atlántida no. 448 de 17 de abril de 1933. CDMH, SE Masonería A, Leg. 404 Exp. 1.
} 
como cónsul de general España. Y más tarde, este último masón solicitará traslado a Nueva York $^{33}$ por medio de los contactos y la referencia de la GLRM, además de querer ingresar en alguna logia de esos valles ${ }^{34}$. Que muchos de estos masones sean judíos, en este caso, sefardíes, responde a una diáspora comercial manifiesta entre el Norte de África y diferentes países latinoamericanos, destacando Argentina, dos de los destinos, preferidos del éxodo judeo-marroquí ${ }^{35}$. Y la prueba de ello fue que la logia tangerina Morayta no. 284, fundada en 1906 y compuesta por una mayoría significativa de judíos a lo largo de su historia (hasta 1932), "seguirá haciendo", en palabras del Gran Maestre del GOE, Martínez Barrios, "la labor que durante muchos años se había impuesto: recoger las aspiraciones de la colonia hebraica tangerina, y servir de órgano de relación entre ella y las de América y oriente $^{36}$ ".

Otro tipo de viajes entre ambas orillas figuran en la documentación consultada hasta ahora $^{37}$. Entre ellos destaca el periplo realizado por Eliseo del Caz, miembro de Oriente no. 451, a diferentes países americanos, donde, además de visitar varias logias, ofreció en las tenidas como visitador, algunas informaciones sobre la política y masonería del protectorado, sobre todo al respecto de las persecuciones sufridas por muchos masones en manos del alto comisario Luciano López Ferrer, además de otros aspectos del proceder de la República ante esta situación ${ }^{38}$. Información que compartió también en la Hispano Americana no. 379 de Madrid, cuyos lazos con los países hispanoparlantes fueron bastante intensos, como bien muestran en sus actividades ${ }^{39}$.

\footnotetext{
${ }^{33}$ Según consta en las actas de la regional, E. Zapico fue obligado a pedir traslado a Puerto Rico con motivo de las persecuciones realizadas a los masones por el entonces alto comisario de España en Marruecos, Luciano López Ferrer. Libro de actas de la GLRM de 7 de marzo de 1933. CDMH, SE Masonería A, Leg. 499 Exp. 2.

${ }^{34}$ No hemos encontrado datos al respecto de su afiliación masónica en logias de Estados Unidos.

${ }^{35}$ Varios son los trabajos desde el campo de la historia que se han realizado al respecto de este último y que tratan esta diáspora, ya histórica en los años 30 del siglo XX, y que relacionan la vinculación comercial de la comunidad judía y su labor dentro de la modernización de Venezuela. En el caso argentino al contrario que en el venezolano, los primeros inmigrantes judíos originarios de Marruecos constituyeron el primer grupo de sefardíes que llegó al país alrededor de 1860, asentándose principalmente en Buenos Aires; extendiéndose sin intermitencias hasta 1970, a pesar de que desde 1930, Argentina limitara la inmigración. Para una visión general sobre la diáspora judía hacia América véase Luisa Pedrique, "La diáspora sefardí en el Nuevo Mundo", Presente y Pasado. Revista de Historia 8 (2003): 203-224.

${ }^{36}$ Memoria de la VI Asamblea Nacional del GOE, 17 de mayo de 1927. CDMH SE Masonería A, Leg. 683.

${ }^{37}$ Los libros de actas de la logia Perseverancia no. 70 o Hércules no. 55 de la GLE, no han podido ser consultados hasta ahora, por lo que quizás la presencia de visitadores, dada la importancia que estas logias otorgan a sus relaciones con América, es mucho más importante de lo que hasta ahora hemos recogido.

${ }^{38}$ Libro de actas de Oriente no. 451 de 21 de octubre de 1933. CDMH, SE Masonería A, Leg. 401 Exp. 1 y expediente personal Leg. 115 Exp. 4. Sobre las persecuciones mencionadas, véase de Paz Sánchez, La masonería y la pérdida de las colonias, 299-348.

${ }^{39}$ Felicitó al presidente de la Argentina por haber abolido la pena de muerte, se dirigió al gobierno de los EEUU para pedirle que concediera la independencia a Filipinas, impulsó la publicación de la revista Mundo Latino, con el fin de estrechar lazos entre ambas orillas, etcétera. Véase Roberto Villa García, "La Logia Hispano Americana no. 379 de Madrid (1915-1935)", en La Masonería en Madrid y en España del siglo XVIII al XXI, coord. Ferrer Benimeli (Zaragoza: CEHME, 2004), vol. 1, 93-114.
} 
En sentido inverso, se han contabilizado algunos visitadores americanos en talleres norteafricanos, sobre todo en la logia 14 de Abril no. 450 de Melilla, en su mayoría judíos. En dos ocasiones aparece A. Samuel Chocrón como visitador procedente de Venezuela, también David Wahnon, de la logia Victoria no. 9 de Caracas visitó la logia en 1934. Anteriormente, en 1933, aparece reseñado un "visitador de Caracas" del que no se especifica ni el nombre ni el taller de procedencia ${ }^{40}$; y en 1931 aparece en la lista de asistencia de la logia el "hermano Gregoire" de los valles de "Port Prince" (Port-au-Prince), la Antigua colonia francesa de Haití. Posiblemente, muchos otros visitantes se contabilizarían en las logias ceutíes y en el resto de las plazas y cuya referencia no se ha localizado aún.

\section{Redes epistolares. Cuantificación y estimación}

Si bien las relaciones entre ambos mundos no fueron tan directas o presenciales, vemos, por el contrario, que su mayor representatividad se encuentra en la correspondencia. Cartas, ternas, garantes e informaciones varias que proliferaron entre las dos direcciones del Atlántico, se han contabilizado, obteniendo los resultados que se indicarán a continuación.

Los talleres de la GLE son los que más contactos presentan, así como los que mayor duración y continuidad establecen en estas relaciones, que irán desde 1931 hasta 1936. A1 contrario, los vínculos de las logias pertenecientes al GOE y la GLRM serán menos asiduos, aunque se plantee en las tenidas, en diferentes ocasiones, iniciarlos o incrementarlos. Por ejemplo, en una tenida de Oriente no. 451 de 17 de marzo de 1932 se aprueba por unanimidad relacionarse con los valles de México ${ }^{41}$; en Atlántida no. 449 pasa a la comisión de asuntos generales "que se acuerden las peticiones de amistad con las logias de los valles de Cuba, Colombia y Egipto" " no. 446 a la logia Armonía no. 28 de los valles de México con fecha de 27 de marzo de 1935: "tratándose de una Resp. Logia de allende los mares que viene a engrosar el no. ya crecido de Resp. Logias con las que sostenemos relaciones fraternales..."43.

En la otra orilla, las logias y obediencias que corresponden a estos contactos o que los inician, proceden en su mayor parte de México, seguido de Cuba, Argentina y Honduras. Aunque se plantearon o mantuvieron relaciones con Colombia, Puerto Rico, Ecuador, Venezuela, Norteamérica y Haití, serán los talleres mexicanos los que más aparezcan entre los garantes de amistad y las planchas de las logias marroquíes.

\footnotetext{
${ }^{40}$ Libro de actas de 14 de Abril no. 450 de 2 de septiembre y 22 de diciembre de 1933 y 31 de marzo y 14 de abril de 1934. También en Moga Romero, Al oriente de África, 461.

${ }^{41}$ Libro de actas de Oriente no. 451 de 17-3-1932. CDMH, SE Masonería A, Leg. 401 Exp. 2-A.

${ }^{42}$ Libro de actas de la cámara de primer grado de Atlántida no. 448 de 6 de febrero de 1933, CDMH, SE Masonería A, Leg. 404 Exp. 1-A

${ }^{43}$ Expediente personal de José Rojo Montes, CDMH, SE Masonería A, Leg. 84 Exp. 4-A.
} 
Las relaciones masónicas son numerosas y abarcan casi la totalidad de la geografía mexicana, destacando, sobre todo, las obediencias de la Gran Logia Unida La OrientalPeninsular de Yucatán, La Gran Logia de Valle de México y la Gran Logia Unida Mexicana de Veracruz. Las tres sostuvieron correspondencia con la GLE mientras que el GOE solo con los talleres de Veracruz. Es probable que hubiera más contactos, o al menos, se estudiara su inicio por parte de la GLRM, como consta en sus libros de actas o en las de sus logias, pero no se han encontrado más evidencias de ello.

Cuba es el siguiente país que destaca en esta red de relaciones, tanto por el trato directo de su obediencia, La Gran Logia de la Isla de Cuba, con la GLRM, como por sus logias Humildad de Guantánamo y Pi i Margal de La Habana, quienes a su vez mantuvieron correspondencia con Hércules no. 446 de Ceuta, Atlántida no. 448 de Tetuán y Perseverancia no. 70 de Larache. Argentina sobresale en tercer lugar, esta vez, por los vínculos directos con este país de muchos masones de las logias marroquíes, como ya se ha señalado, tanto por ser su lugar de procedencia o de destino como por diferentes felicitaciones y comunicaciones por parte del GLRM a la logia Hispano-Argentina de Buenos Aires ${ }^{44}$, o bien, directamente, por el decreto del GCFS del GOE de 1935 que indicaba a las logias de su obediencia que entablaran relaciones con talleres de esta República argentina. Se conserva en las actas de Lixus no. 446 B de Larache la referencia de este hecho ${ }^{45}$.

Con menor representatividad se encuentran las relaciones establecidas con Honduras, Puerto Rico, Ecuador, Colombia, sobresaliendo entre ellas, las logias Estrella del Norte no. 5 de Honduras, con quien también otros talleres peninsulares mantuvieron relaciones $^{46}$ o Guayas no. 1 de Ecuador. Otros países como Brasil, Venezuela o Filipinas aparecen en la documentación consultada, pero por las conexiones más directas indicadas en el apartado anterior.

\section{Evolución y durabilidad}

Las relaciones epistolares se inician desde 1931, año en el que se levantan la mayoría de las logias españolas en el territorio colonial magrebí, alcanzando su apogeo una vez están estabilizadas en sus respectivas plazas entre 1933 y 1934, momento a partir del cual comienzan a descender hasta el final de los contactos en 1936. La evolución de estos

\footnotetext{
${ }^{44}$ Cartas en 1932 (19-12-1932) a diferentes logias para felicitar el solsticio de inverno, entre ellas, la HispanoArgentina de Buenos Aires. En el Libro de registro de entrada y salida de correspondencia de la GLRM. CDMH, SE Masonería A, Leg. 500.

${ }^{45}$ Libro de actas de cámara de primer grado de Lixus no. 446B, 7-12-1935. Decreto del GCFS con la suspensión de las logias de Tetuán y dando instrucciones para las relaciones que pudiéramos entablar con taller de la República Argentina.

${ }^{46}$ Yván Pozuelo constata esta relación para el caso de la masonería asturiana. Pozuelo, "Las relaciones masónicas entre Asturias e Hispanoamérica", 268.
} 
vínculos según las obediencias, es clara a priori: las logias de la GLE superan en número e intensidad en relación con las el GOE. Y, si tenemos en cuenta la variable de la GLRM y las restantes de Melilla y Ceuta que pertenecen a la Gran Logia Regional del Mediodía de España (GLRME), se añade un resultado disímil: la primera de ellas ofrece una caída continua desde 1934 hasta desaparecer en 1936, mientras que la segunda, si bien presenta un desliz en 1935, en 1936 se vuelve a intensificar su red de relaciones latinoamericanas.

Estos contactos, además, fueron iniciados por ambas partes, es decir, tanto por las logias marroquíes que eran de más reciente creación, como por las americanas, cuyo desarrollo histórico varía: algunas habían sido fundadas a principios del siglo XX o con anterioridad $^{47}$ como Esperanza no. 2 de Veracruz, constituida en 1869, o bien como Humildad de Cuba instaurada en 1909, Fénix no. 18 de Mérida en 1922, pero otras, como Reforma no. 33 de Veracruz que levantaría sus columnas en 1929, son de configuración contemporánea $^{48}$, como las norteafricanas, por lo que es obvio el interés compartido de establecer contactos y reconocimiento masónico internacional. Algunas de las logias americanas que iniciaron las relaciones con las norteafricanas fueron Estrella del Norte no. 5 de Honduras en 1934, que inicia los contactos con Hércules no. $55^{49}$ o Armonía no. 28 de México con Hércules no. 446 en $1935^{50}$, a pesar de ser, como indican en las cartas, "del Libre Simbolismo". La logia Tenochtitlán de México también establece el primer contacto epistolar con el taller ceutí Hércules no. 5, en 1935. Del mismo modo, Reforma no. 33 de México le comunica a esta última que Lumen no. 6 les pasó los listados de las logias de Amistad que tenía "teniéndose en cuenta la gran necesidad que hay [de] que todos los masones esparcidos por la Faz del universo estemos unidos espiritualmente",51.

En cualquier caso, esta red se afianza entre 1932 y 1934 obedeciendo a la estabilidad y consolidación de las logias en el territorio marroquí, así como al interés de las logias latinoamericanas en fomentar o ampliar los vínculos fraternales con las españolas. Destacará en esta labor de relaciones y vínculos la GLE, tanto por su geopolítica propia, como por el venerable maestro de Perseverancia no. 70, Bartolomé Pajares ${ }^{52}$, una de las figuras más destacables de la masonería en el protectorado marroquí y del establecimiento y la prolongación de los contactos con América. De hecho, el número de garantes de

\footnotetext{
${ }^{47}$ Conocemos el año de la fundación de muchas de estas logias porque se incluían en las cartas que enviaban.

${ }^{48}$ La situación de la masonería mexicana, por ejemplo, en estas fechas era bastante irregular e inestable, es decir, muchas logias cambian de número de registro u obediencia, o bien se crean nuevas, lo cual hace difícil precisar y hacer un seguimiento exacto de las relaciones.

${ }^{49}$ Según consta en la plancha "Excusamos deciros el júbilo con que ha sido cogida vuestra plancha ya que no teníamos correspondencia ni relaciones con ningún Resp. Taller de Honduras y celebramos de todo corazón la iniciación de estas relaciones que confiamos serán todo lo estrechas en bien de nuestra". CDMH, SE Masonería A, Leg. 84 Exp. 22.

${ }^{50} \mathrm{CDMH}, \mathrm{SE}$ Masonería A, Leg. 84 Exp. 4.

${ }_{52}^{51} \mathrm{CDMH}, \mathrm{SE}$ Masonería A, Leg. 33 Exp. 3.

${ }^{52}$ Bartolomé Pajares fue nombrado para ostentar los Garantes de Amistad de Perseverancia no. 70 de: Tolerancia Masónica no. 6 de México, Esperanza no. 2 de Veracruz, Fenix no. 18 de México, Renacimiento no. 1 de Mérida, Obreros del Porvenir no. 19 de Yucatán, etcétera.
} 
amistad para los que fue nombrado, muestran a la perfección este hecho. De igual modo, en su misma logia, destacan José González Lagares ${ }^{53}$ y Guillermo Vázquez ${ }^{54}$, cuyos nombramientos como garantes también son considerables, sobre todo a partir de 1936 con la muerte de su Venerable B. Pajares. Este suceso, bien conocido por parte de las logias con quienes mantenían correspondencia, fue objeto de reconocimiento y pesar a ambos lados del Atlántico, lo que supuso un aumento de su red epistolar. Es por ello que los vínculos de la GLE, en concreto de Hércules no. 55 de Ceuta y Perseverancia no. 70 de Larache con Latinoamérica se mantienen altos, a pesar de que la propia situación política de 1934 también les afectase. La consistencia y la cohesión interna de estas logias, sobre todo de Perseverancia, supuso que no menguaran sus trabajos hasta el mismo día en el que se alzó el "Glorioso Movimiento Nacional" en el territorio magrebí el 17 de julio de 1936. Es más, existe una continuidad en la correspondencia mantenida entre logias, algunas de las cuales oscilan entre 1932 y 1936 como sucede entre Perseverancia y Tolerancia Masónica no. 6 de Nuevo León o entre Perseverancia y Obreros del Porvenir no. 19 entre 1934 y 1936. En otros casos, como en las relaciones del taller de Larache y Esperanza no. 2 de Veracruz, la documentación conservada solo cubre 1933 y 1934 pero con una gran cantidad de epístolas, cuyos intercambios de informaciones, prensa o trabajos son realmente considerables. Parece, en este sentido, que los vínculos continuaron, a pesar de que aún no se hayan encontrado evidencias textuales de ellos. Puede este ser el mismo cuadro de muchas otras logias y relaciones, como las logias cubanas o la hondureña Estrella del Norte no. 5. Las planchas mantenidas con Humildad de Guantánamo por parte de las logias de la GLE y del GOE, sobre todo de la GLRM, van desde 1933 hasta 1936, y con el taller hondureño se mantienen entre 1933 y 1934 con cierta regularidad, en esta ocasión sus protagonistas fueron Hércules no. 55, Oriente no. 451 y Cabo Espartel no. 447, estas dos últimas bajo los auspicios de la GLRM.

Siguiendo el desarrollo cronológico, la evolución de las relaciones de las obediencias que hemos establecido -GLE, GLRM-GOE y GOE- presentan características similares a nivel general, por ejemplo, la revolución de octubre de 1934 condujo a España a un Estado de alarma oficial acompañado de un estado de represión permanente contra el movimiento obrero y el republicano que solo la victoria del Frente Popular en las elecciones de febrero de 1936 pudo frenar. A ello se añadía el giro político de derechas en la política de la República que marcó por igual a toda la masonería española, produciendo unos meses de inestabilidad en la orden a nivel nacional. Es representativa, en este sentido,

\footnotetext{
${ }^{53}$ José González Lagares, orador de Perseverancia no. 70 tiene garante de amistad con Fraternidad no. 3 de Mérida, por ejemplo, y además, sustituye como garante de Esperanza no. 2 de Veracruz a Bartolomé Pajares, después de su muerte en 1936.

${ }^{54}$ Guillermo Vázquez, secretario de Perseverancia no. 70 tiene garante de amistad con Estabilidad no. 16 de Mérida y otras logias mexicanas.
} 
la respuesta de la GLRM a la plancha enviada por la Gran Logia Unida Mexicana de Veracruz el 27 de febrero de 1934:

Recogemos vuestras frases de aliento y os participamos que la Masonería en España, aunque un poco tarde quizás, se dispone a defender sus principios, seriamente amenazados por la reacción, y a que nuestra amada y querida República se encamine nuevamente por la senda que se trazó al nacer. ${ }^{55}$

La GLRM sufre un hecho añadido en el transcurso de estas relaciones, y es su propia desestructuración a lo largo de 1934 y su fin definitivo en 1935. Algunas logias sobrevivieron a esta desintegración, como Lixus no. 446B, Cabo Espartel no. 447 o el Triángulo Lombroso ${ }^{56}$, por lo que los pocos contactos que quedan de las logias del GOE en 1935 corresponden a aquellas que continuaron sus trabajos después de la disolución de la regional o bien las que pertenecían a la GLRME, ubicadas en Ceuta y Melilla, aunque de modo menos regular que en 1933 y 1934.

El fin de todos los contactos, por supuesto, está claro. Los únicos residuos de correspondencia que hemos encontrado de algunas de las logias aquí mencionadas, están dirigidos a logias peninsulares, sobre todo de Barcelona, que aún en 1937, año de estas epístolas, sigue vigente la masonería. La situación en Marruecos en estos momentos previos a la Guerra Civil y peor aún en 1936, resultó bastante más inestable y compleja que en el resto de España, dado el gran sector fascista que había entre los militares africanistas y el peso social que tenían en la sociedad, hasta el punto de que algunos autores han hablado de una mayor diferencia entre civiles y militares que entre españoles y musulmanes, los nativos de la zona y, al fin y al cabo, la mayoría de la población ${ }^{57}$. Del mismo modo, la persecución a los masones en manos de este sector fue constante durante todo el periodo republicano, sobre todo en Tetuán y en las logias de esta zona, en la que sus miembros más destacados sufrieron continuos ataques, despidos o traslados con una gran intensidad en 1932 y de nuevo a partir de 1934 y 1935, como se ha citado más arriba. En 1932, la razón principal fue el nuevo alto comisario, Luciano López Ferrer ${ }^{58}$, quien intentó combatir la masonería desde su llegada al cargo en junio de 1931. Los masones de estos talleres norteafricanos lucharon contra estas persecuciones y una de las acciones realizadas fue,

\footnotetext{
${ }^{55}$ CDMH, SE Masonería A, Leg. 86 Exp. 1.

${ }^{56}$ Quedan algunas referencias de que en 1935 y 1936 continuaban sus trabajos. CDMH SE Masonería A, Leg. 28 Exp. 3; Leg. 421; Leg. 605, Exp. 4. El primero corresponde al Venerable Maestro de Lombroso, Vicente Arlandis Marzal, el segundo al Libro de actas de la cámara de primer grado de Lixus no. 446B, y el tercero al Libro de actas de la cámara de primer grado de Cabo Espartel no. 447.

${ }^{57}$ Mateo Dieste, "Una hermandad en tensión”, 79-96.

58 Fue diplomático español, cónsul de Tetuán en 1915, secretario de la Alta Comisaría de España en Marruecos desde 1921 hasta 1923, alto comisario desde junio de 1931hasta enero de 1933; y embajador en Cuba en 1933. Véase María Rosa de Madariaga, "La II República en el protectorado: reformes y contrarreformas administratives y burocráticas", $A W R A Q$ 5-6 (2012): 97-115.
} 
precisamente, avisar a sus "hermanos americanos" de lo que estaba sucediendo en el protectorado tanto por correspondencia como por el viaje que hemos mencionado de Eliseo del Caz a esos valles. El lazo de unión se terminó de aferrar cuando se destituye a López Ferrer de su cargo en la Alta Comisaría en enero de 1933 y se le destina a Cuba como embajador. Ante ello, la GLRM avisa sin demora a la Gran Logia de la Isla de Cuba, señalando que este individuo es "enemigo a muerte de la Orden, de la libertad y de la democracia" ${ }^{29}$.

\section{Tipología y contenido de la correspondencia}

La tipología de esta red epistolar forma un amplio abanico de variedades, como ya se ha podido dilucidar durante las páginas anteriores. Los primeros contactos fueron meramente formales: felicitaciones de año nuevo o por los solsticios, el deseo de establecer amistad, las ternas propuestas y los garantes de amistad que, al fin y al cabo, eran la demostración textual, simbólica y legítima del establecimiento de las relaciones de amistad. Junto a estas formalidades se añadían los resultados de las elecciones anuales a cargos y dignidades, los cuadros lógicos del taller, los resúmenes de los trabajos realizados, alguna fotografía del masón que ostentaba el título, etcétera. De hecho, la totalidad de la correspondencia analizada tiene alguno o todos estos ítems.

No obstante, algunos de los vínculos fueron más allá, logrando establecer un contacto continuo de informaciones, trabajos y colaboración masónica en ambas direcciones. Por ejemplo, Edmundo Seco Sánchez de la logia Cabo Quilates no. 11 de la GLRM, dedicó un "trazado de arquitectura" a Esperanza no. 2 de Veracruz por el 65 aniversario de la logia mexicana ${ }^{60}$. Ya hemos nombrado otros más arriba, sobre todo ligados a la logia Perseverancia no. 70, cuyos intensos y constantes trabajos internos produjeron diferentes escritos y publicaciones que se enviaban a través de esta red epistolar. El pequeño cuaderno sobre la Memoria Anual de $1933^{61}$, el folleto tan conocido y polémico ¡Abajo el Fascio! ${ }^{62}$ en ese mismo año, fueron felicitados por diversas logias americanas, como por ejemplo Obreros del Porvernir no. 19 y Fénix no. 18 de Yucatán, Esperanza no. 2 de Veracruz o Humildad de Guantánamo. ¡Abajo el Fascio!, entre estos escritos, produjo una fuerte reacción, sobre todo porque Bartolomé Pajares fue procesado y sometido a juicio como autor del mismo, y los ejemplares fueron retirados de circulación. Este hecho

\footnotetext{
${ }^{59}$ La GLRM avisa a diferentes logias cubanas (no se especifica cuáles) de la llegada de L. Ferrer. Libro de actas de la GLRM de 7 de marzo de 1933. CDMH, SE Masonería A, Leg. 499 Exp. 2.

${ }^{60}$ Villa Alhucemas, marzo de 1934. CDMH, SE Masonería A, Leg. 198 Exp. 9.

${ }^{61}$ Presentada por Guillermo Vázquez Castillo "en la última tenida del año seguida del banquete solsticial que se celebró el 31 de diciembre de 1933 (era vulgar). Nota adicional del hermano José González Lagares", impresa por la tipografía La Ibérica en 1934, cuyo dueño era Bartolomé Pajares en Larache. CDMH, SE Masonería A, Leg. 803.

${ }^{62}$ Publicado por la La Ibérica, Larache, 1933. CDMH, SE Masonería A, Leg. 803.
} 
despertó en la masonería española y en las logias americanas la misma aversión hacia el componente fascista -en un régimen supuestamente republicano y liberal- ${ }^{63}$, que lo había consentido:

Mucha fue nuestra pena de enterarnos de que había sujeto a proceso por la justicia profana por expresar sus ideas libres y soberanas, pero mayor ha sido nuestra satisfacción al saber que salió limpio y con la frente en alto, dispuesto a castigar a los ambiciosos que se dedican a comerciar con el obscurantismo de masas ${ }^{64}$.

El abogado que llevó el caso, también masón, José Alberola Feced ${ }^{65}$, quien había sido el primer gran maestro de la GLRM, procedió a su defensa consiguiendo la absolución. Todos estos acontecimientos -al igual que la muerte de Pajares en 1936- estaban a la orden del día en las logias latinoamericanas con quienes mantenían relaciones.

Además de ello, hubo otros textos, adjuntos a estas cartas, que destacaron por la temática tratada. Por ejemplo, en una carta a Estabilidad no. 16 de Mérida, Guillermo Vázquez de Perseverancia no. 70, comentaba a los miembros de esta logia "los dos asuntos primordiales que se debaten hoy en nuestra Patria" , comparándolos con la situación de los países latinoamericanos:

Las luchas de la libertad y bella México por ese su independencia espiritual, temiendo combatir denodada y virilmente contra los enemigos de la libertad, la hace conocer más de cerca la lucha que hemos de sostener los masones de la familia española, para derrocar este poder del clericalismo, que se defiende como puede y utiliza todos los medios antes de entregarse ${ }^{67}$.

En otra carta anterior a esta, de Bartolomé Pajares a Esperanza no. 2, resulta también muy ilustrativo la narrativa sobre los lazos culturales e históricos latinoamericanos con el desarrollo de la masonería en esta latitud y el ejemplo que debe ser para la masonería española contemporánea, sobre todo "para dar principio a una correspondencia

\footnotetext{
${ }^{63}$ Esta es la crítica que hacían constantemente los masones de Marruecos en sus cartas al GCFS del GOE o incluso a los propios ministros como Diego Martínez Barrios.

${ }^{64}$ Plancha de Esperanza no. 2 a Perseverancia no. 70 el 29 de marzo de 1934. CDMH, SE Masonería A, Leg. 84 Exp. 11.

${ }^{65}$ Fundador de Atlántida no. 449, venerable de esta logia hasta que ostenta el cargo de primer Gran Maestre de la GLRM. Ocupó este puesto de 1932 a septiembre de 1933, momento en el que se le suspende

${ }^{66}$ Perseverancia no. 70 a Estabilidad no. 16 de Mérida el 20 d enero de 1934. CDMH, SE Masonería A Leg. 84 Exp. 23.

${ }^{67}$ En la carta se extiende contando cómo han elevado a su Supremo Consejo dos escritos, uno por las nuevas elecciones de la República que fueron encauzadas hacia la derecha y otro por el proyectado articulo 26 de la constitución, pues suponía terminar con el laicismo del Estado español. Perseverancia no. 70 a Estabilidad no. 16 de Mérida el 20 de enero de 1934. CDMH, SE Masonería A Leg. 84 Exp. 23.
} 
ininterrumpida, no solo entre logias hermanas, sino entre masones de repúblicas que si esta fue madre de aquella por nacimiento, aquella es madre de esta por ideal"68.

En sentido inverso, el proceso fue similar. Por ejemplo, Esperanza no. 2 de Veracruz envió varias copias de la revista Simbolismo ${ }^{69}$ de la Gran Logia Unida Mexicana a la logia de Larache y a Constancia no. 89 de Ceuta y, a su vez, solicita a Atlántida no. 449 y a Cabo Quilates no. 11 trabajos para la tenida extraordinaria que celebrará el 10 de enero de $1934^{70}$ a propósito de su 65 aniversario. Memphis de México le comunica en varias cartas a Hércules no. 55 de Ceuta los trabajos que realizan ${ }^{71}$, la logia Guayas no. 1 de Ecuador también envía su Boletín en 1933 a la logia 14 de Abril no. 450 de Melilla ${ }^{72}$, etcétera La Gran Logia de la Isla de Cuba también se une al envío de informaciones a la GLRM, por el hecho de avisar de que un masón, Martín Velilla Nadal de la logia Pi y Margall de La Habana, está suspenso y procesado por tribunales masónicos y profanos ${ }^{73}$.

Sin embargo, existe una diferencia en el contenido de las planchas que los talleres americanos ofrecían a los norteafricanos: escasas referencias a su situación política o social de su propio país. Del mismo modo que apenas hacen referencia a la situación del protectorado español en Marruecos. La mayor parte de las veces, como hemos reflejado, los temas tratados o son de contenido interno de las propias logias o abarcan la política española general. Y este último caso es el que más impregna los documentos, probablemente por la época convulsa en la que se enmarcan y los deseos de que triunfen y se consoliden los ideales republicanos que, al fin y al cabo, iban en comunión con los preceptos masónicos defendidos desde ambas orillas. Así lo demuestra, por ejemplo, La Gran Logia de la Isla de Cuba cuando escribe en 1933 a Hércules no. 446 de Ceuta que, "nuevamente se la mandamos hoy dirigida a la Logia [la plancha], esperando que esta vez llegue a su destino, ya que entendemos que con el cambio que ha dado la política española y sus Gobernantes podrá la masonería salir ya a la luz pública"74.

Por otra parte, la red epistolar masónica fue más allá del intercambio de los trabajos realizados, los folletos y la prensa enviada o las diferentes informaciones que se traspasaban, llegando a una colaboración más práctica y a una unión más ponderable. Por ejemplo, Obreros del Porvenir no. 19 solicita ayuda económica a Perseverancia no. 70 para la construcción de su templo en 1936 "para realizar unas "pláticas (tenidas blancas) encaminadas a desvanecer los efectos de tales enemigos del progreso y la civilización"75. O

\footnotetext{
${ }^{68}$ Perseverancia no. 70 a Esperanza no. 2 el 28 d marzo de 1933. CDMH, SE Masonería A Leg. 6 Exp. 11.

${ }^{69}$ Revista de la Gran Logia Unida de Veracruz, desde 1898, VVAA, International Masonics Periodicals, 1798-2005 (2006), 290.

${ }^{70}$ CDMH, SE Masonería A, Leg. 144 Exp. 24.

${ }^{71}$ CDMH, SE Masonería A, Leg. 108 Exp. 18.

${ }^{72}$ Libro de actas de cámara de aprendiz de 14 de Abril no. 450, acta de 12 de mayo de 1933. CDMH, SE Masonería A. Leg. 429 Exp. 2.

${ }^{73}$ CDMH, SE Masonería A, Leg. 27 Exp. 17.

${ }^{74}$ CDMH, SE Masonería A, Leg. 27 Exp. 17. Remitida el 4 de julio de 1933.

${ }^{75}$ CDMH, SE Masonería A, Leg. 203 Exp. 11. Con fecha de 10 de febrero de 1936.
} 
bien, en abril de 1936, un miembro de la 14 de abril -Julio Antonio Herranz Pérez-, a su vuelta de un viaje a Madrid, expuso cómo había presenciado la llegada a la capital de España de unos masones de Puerto Rico en busca de ayuda de sus "hermanos peninsulares"76.

Asimismo, se mantienen otro tipo de inter-colaboraciones como se observa en una carta dirigida a Bartolomé Pajares desde una logia de San Luis de Potosí, sin especificar, realizada con el motivo de conocer la posibilidad "de que un buen cirujano-dentista"77 pueda iniciar su negocio en los valles de Alcazarquivir. No obstante, de entre todas las cooperaciones que se observan en las fuentes consultadas destaca, por su singularidad, la correspondencia entre nuestras sin duda protagonistas Perseverancia no. 70 de Larache y Esperanza no. 2 de Veracruz, quienes incentivan una propuesta sobre un vuelo entre México y España en 1934 en manos del General de la Aviación Mexicana, Carlos Castillo Bretón Barredo, ${ }^{78}$ miembro de la logia Regeneración no. 14 de Veracruz:

La iniciativa de ese vuelo México-España nos ha llenado de tal manera de satisfacción, que (...) trataremos de contribuir con vosotros para la adquisición de esa máquina que el Q. y V. H. Carlos Castillo Bretón B., juzga necesaria para "que asegure hasta lo posible y humano esfuerzo, el triunfo y la gloria para México", auxilio el nuestro, que habrá de ser en armonía con nuestra modestia, pero que tendrá todo el valor del entusiasmo y el cariño que la idea ha despertado en $\operatorname{nosotros}^{79}$.

El vuelo simbolizaba, para Perseverancia, la unión fraternal entre ambos países, cuya misión ya había sido lograda -a medias- en otra ocasión en una ruta entre Sevilla, La Habana y México ${ }^{80}$, por otro masón, “el teniente Collar, en unión de su compañero el

\footnotetext{
${ }^{76}$ Libro de actas de cámara de aprendiz de 14 de Abril no. 450, Acta de 2 y 9 de abril de 1936. CDMH, SE Masonería A. Leg. 429 Exp. 2.

${ }^{77}$ Carta enviada por Carlos Hersch de San Luis de Potosí el 5 de marzo de 1933. CDMH, SE Masonería A, Leg. 15 Exp. 7.

${ }^{78}$ Comodoro de Piloto Aviador mexicano fue precursor de la aeronáutica naval mexicana, concediendo grandes aportaciones a al Primer Escuadrón Aeronaval de la Armada de México. Tuvo en mente en los años 30, la realización de un vuelo transatlántico México-Sevilla que no pudo retomar hasta 1935 cuando se le nombró Jefe del departamento de Marina, de la Secretaría de Guerra y Marina. Véase Argeñ Armador Martínez, "Comodoro Carlos Castillo Bretón Barredo", en Militares y marinos destacados, edición de Fuerzas Aéreas y Marina de México (México: Secretaría de la Defensa Nacional, Dirección General de Comunicación Social, Sección de Difusión Interna, 2011), 333-339.

${ }^{79}$ Perseverancia no. 70 a Esperanza no. 2 el 4 de diciembre de 1933. CDMH, SE Masonería A, Leg. 6 Exp. 11.

${ }^{80}$ Se trata del famoso vuelo del avión Cuatro Vientos realizado en 1933 por Mariano Barberán y Joaquín Collar, que saldría el 9 de junio de ese año de Madrid, pasando por Sevilla; llegando a Cuba, en concreto a Camagüey, el día 11 de junio. El día 12 la ruta continuaría hasta La Habana, el lugar previamente fijado de llegada, donde les recibieron miles de personas, y el 20 de junio se prepararon para partir hacia México y de ahí tomar rumbo hacia Estados Unidos, donde habían sido invitados a la Feria Internacional de Chicago. La previsión de la llegada a México, primera parada antes de Norteamérica, era a las 13:40 horas, pero hubo
} 
Capitán Barberán, ambos caídos gloriosamente en la magna empresa de afianzar el cariño entre dos pueblos hermanos, de raza y por temperamento y convicción" 81 . A su vez, significaba la demostración de la modernización y la capacidad tecnológica de ambos países (México-España). Sin embargo, a pesar de los esfuerzos mantenidos por ambas durante diversas cartas entre diciembre de 1933 y marzo de 1934, este vuelo no llegó a realizarse en 1934 como se había previsto, ni en 1935 tras haber sido pospuesto. La razón de ello fue la repentina y sorpresiva muerte del General Bretón el 19 de septiembre de 1935.

En definitiva, lo que más destaca en la tipología y el contenido de estas relaciones son las continuas alusiones a la política republicana española, al devenir de la masonería en este marco convulso, el buen camino de las masonerías americanas y cómo desean siempre que los ideales masónicos imperen en estos regímenes. Nada extraño, pues, de hecho, en uno de los boletines del GOE se hace alusión al beneficio de que muchos políticos españoles fuesen masones ${ }^{82}$. E, incluso, la logia Humildad de Guantánamo, que había mantenido contactos con las logias norteafricanas de las dos obediencias españolas, continúa su vínculo en 1937 con Minerva no. 25 de Barcino -pues la masonería española en Marruecos ya había sido eclipsada por el Glorioso Movimiento Nacional. En esta epístola, como es lógico, casi solo se hace alusión al devenir de España:

Quiero significaros que mi Logia ha tomado Acuerdos en distintas ocasiones, en pro de todos los Masones españoles por el atropello de que han sido objeto por las huestes facciosas demandadas por Franco y sus secuaces, que parece les molesta que el sol de la Libertad brille con todo su esplendor en nuestra querida Patria ${ }^{83}$.

\section{Algunas valoraciones: redes globales}

A lo largo de estas páginas, hemos intentado establecer una visión general de la importancia y la significación de las relaciones francmasónicas entre las logias norteafricanas y las latinoamericanas durante la II República española. A través del análisis de la correspondencia mantenida y otras fuentes complementarias, se han destacado algunas consideraciones generales que se han ido señalando en el transcurso de este trabajo: la conformación de una red epistolar que configuró a su vez una red de relaciones masónicas transcontinental, recíproca y bidireccional, la importancia de algunas personalidades en la

\footnotetext{
dificultades: se desató una tormenta inesperada por lo que a las 20: 30 horas aún no había aparecido el Cuatro Vientos. Desde México se organizó la búsqueda en torno a $300 \mathrm{~km}^{2}$ sin encontrar ningún resto o señal del avión o la tripulación. Véase Antonio G. Betes, "Cincuentenario del vuelo Sevilla-Camaguey", Aeroplano, Revista de Historia Aeronáutica 1 (junio de 1983), http://www.ejercitodelaire.mde.es/stweb/ea/ficheros/pdf/34BBB165546B71ADC12574DD00226847.pdf

${ }^{81}$ Betes, "Cincuentenario", 1983.

${ }^{82}$ Boletín del Gran Oriente Español, 10 de enero de 1933, 12. Pozuelo, "Relaciones y opiniones oficiales", 211.

${ }^{83}$ CDMH, SE Maonería A, Leg. 202 Exp. 9.
} 
intensidad y la densidad de los contactos establecidos, como el caso de Bartolomé Pajares de Perseverancia no. 70 y de esta misma logia; el protagonismo también acentuado de la comunidad hebrea por sus vínculos directos con América; o bien que, tanto el inicio como el fin de los contactos así como del establecimiento de la red, están marcados ligeramente por el contexto político de la II República que influyó en su creación y consolidación, así como en su precariedad y desaparición.

De hecho, si comparamos los resultados obtenidos en este estudio con los proporcionados por los boletines de las respectivas obediencias, vemos que la tendencia es similar a cada una de ellas. Así, en el Boletín del GOE, tomando los datos obtenidos del artículo ya mencionado de Yván Pozuelo ${ }^{84}$, Argentina recibe un trato de los más importantes en el seno del BGOE y casi nulo desde los órganos de la GLE, y México sería uno de los "pesos pesados", en términos del autor, de ambas obediencias. La tercera potencia en estas relaciones corresponde a Cuba, el resto de países tienen mayor o menor representación según la fecha o las circunstancias. En cambio, el Boletín de la GLE refleja otros datos, también similares a la tendencia de la red epistolar que aquí nos ocupa. Si bien esta obediencia tenía en términos de número de talleres y de miembros, cifras muy inferiores a las del GOE (también en las logias norteafricanas), les concedió mayor importancia a sus vínculos internacionales, por ejemplo, a la AMI, y, además, mantuvo un proselitismo acentuado en relación a cualquier movimiento masónico surgido en Latinoamérica, anunciando cuanto antes la creación de una nueva entidad y su voluntad de entablar correspondencia institucional.

No obstante, si establecemos otra comparación, esta vez entre los contactos que establecen las logias norteafricanas que nos ocupan con otros territorios más cercanos, como, por ejemplo, el protectorado francés, Argelia, Egipto, Francia y otras comunidades o provincias españolas, la balanza se decanta hacia el otro lado del Atlántico, lo cual resulta bastante significativo. Es cierto que no se pueden establecer analogías con aquellos talleres españoles que nutrieron los africanos, como el caso de los andaluces, o bien las relaciones con las logias situadas en la misma sede que las obediencias, como el caso de Madrid, Barcelona o los talleres españoles del protectorado francés pertenecientes a la GLRM, pues son más numerosas, imprescindibles y obvias las comunicaciones. Pero, en cambio, sí es representativo que los contactos que hemos podido contabilizar en un balance inicial con la masonería americana fueran más asiduos, o fuesen más relevantes no sólo por su número sino por la continuidad manifiesta en las fuentes consultadas que en otras zonas geográficamente más próximas o con lazos de unión más similares: por la población judía o

\footnotetext{
${ }^{84}$ Pozuelo, "Relaciones y opiniones oficiales", 134. Este autor nos ofrece los porcentajes exactos: en las páginas de los boletines oficiales, la GLE supera al GOE en número de referencias sobre Iberoamérica en un $35 \%$ sobre el periodo de 1931-1934. Argentina no es tan importante como en el caso del GOE, y de resto se mantiene igual solo que en algunos casos superan en noticias e informaciones. La GLE se centra sobre todo en Puerto Rico, cuya obediencia compartió la misma línea de actuación en el seno de la AMI y se nombran los garantes de amistad con Venezuela, Uruguay, Chile, El Salvador y México.
} 
musulmana presente en las logias del protectorado o por la condición colonial inherente en esta masonería norteafricana, que en nada se relaciona con el panorama sociocultural que definía a los diferentes países latinoamericanos con los que contactaron y sí con otros africanos, por ejemplo con la vecina Argelia, la zona de influencia francesa o Tánger ${ }^{85}$. Si bien existieron relaciones más directas por la cercanía geográfica: visitadores procedentes de logias de Orán, Rabat, El Cairo, Uxda aparecen en alguna ocasión en las tenidas de Atlántida no. 448, por ejemplo, de la logia egipcia Luz y Ciencia (Nor y Jokma), además de los nombramientos de garantes de amistad con varias logias de las zonas nombradas. A esto se le añaden los contactos con el taller Plus Ultra de París, Conscience de Rabat entre otras logias del Gran Oriente Francés. Pero estos vínculos se deben, sobre todo, a las logias del GOE y no a las de la GLE. Podemos establecer, por tanto, que estos contactos fueron más comunes con las logias del GOE, precisamente por su proyecto masónico en el territorio del protectorado, con la constitución de la GLRM y el deseo de configurar un crisol de culturas en el Norte de África, dada su característica multiétnica y la labor protectora de España propia de la retórica colonial africanista. La GLE, en cambio, centra sus esfuerzos en consolidar los vínculos ya históricos y culturales con América, como bien lo demuestra su boletín. No obstante, la variedad de fuentes consultadas, incluso las propias de la GLRM, presentan una mayor relación, al menos más allá de la formalidad masónica de estos casos, con los talleres latinoamericanos, sobre todo mexicanos, que con otras zonas más cercanas, exceptuando Francia. No por casualidad fueron estos dos países, México y Francia, los que acogieron a muchos exiliados masones y republicanos en su territorio.

Por otro lado, si tenemos en cuenta la visión de estas relaciones por cada una de las masonerías aquí tratadas, se puede establecer que se entiende a la masonería marroquí, desde los talleres americanos, como parte de la masonería española general y no con ningún cariz periférico ni colonial. La importancia de la orden en España y la política de la II República en el contenido de la mayoría de las cartas, supone un interés general para el mundo masónico americano, sin puntualizar en ningún caso las cuestiones concretas al respecto del protectorado, y si se menciona, es para avalar de forma genérica la misión o la labor de España en este territorio. Del mismo modo que la masonería justificó la esclavitud o colonización en algunos países latinoamericanos en el siglo XIX, las logias españolas durante la II República y los talleres americanos con quienes establecen contactos, no solo comprendieron y justificaron el protectorado y la acción colonial de España en Marruecos sino que, más bien, no distinguen su estatus diferencial del resto del territorio peninsular, a pesar, incluso, de los propios procesos coloniales e independentistas experimentados en América. También, la masonería americana se comprende, por los talleres del Magreb como una unidad geopolítica, aunque existan diferencias cuantitativas y cualitativas tanto en los contactos como en la densidad de las redes. Latinoamérica y los diferentes países con

\footnotetext{
${ }^{85}$ Nos referimos, en estos dos últimos casos, a las logias fuera de la jurisdicción de obediencias españolas.
} 
quienes se establecen vínculos significaban, en sentido amplio y sin distinción, el triunfo de la libertad y la independencia de los pueblos, la victoria de las ideas republicanas y los preceptos masónicos. En este sentido, el análisis de los discursos de ambas partes se vuelve esencial para comprender no solo las nociones al respecto de los territorios y las acciones desarrolladas por la orden en cada uno, sino las interconexiones e interrelaciones que se derivan de ellos y que se analizarán en profundidad en próximos trabajos.

Para concluir, quisiéramos destacar la importancia y la relevancia de estas relaciones por la conformación de una red masónica, transoceánica y transcontinental dentro de un contexto inminentemente global y globalizado. La masonería española marroquí, desde la periferia y su situación colonial, estableció diferentes vínculos que le proporcionaron reconocimiento, legitimidad y una red de sociabilidad y solidaridad con Latinoamérica, aprovechando los vínculos históricos, culturales, pero, sobre todo, ideológicos, con este continente. Y a pesar de su formalidad, no solo propiciaron las relaciones fraternales entre ambas orillas, sino que superaron en intensidad las conexiones de los talleres magrebíes con otros geográficamente más próximos, complejizando y reconfigurando con ello la red de relaciones masónica internacional.

En definitiva, esta red masónica conformada en medio del imperialismo europeo, también estaba inserta en el desarrollo de la globalización del mundo, es decir, en la concepción global de este, cuyas bases comenzaron a implantarse desde el siglo XVIII y, no por casualidad, estuvieron motivadas e incentivadas por la propia dinámica de la masonería. La comprensión del mundo como un todo o bien la intensificación de la conciencia del mundo de un modo integral, es una condición inherente de la sociabilidad masónica. El mundo, cada vez más interconectado e interdependiente, conectado a nivel global, tiene su máxima expresión en la masonería y, en nuestro caso, en la masonería norteafricana, donde convergen y divergen Europa, África y América, pero también, musulmanes, españoles, franceses, americanos, judíos, cristianos y toda una amalgama pintoresca de actores diferentes unidos por una forma concreta de entender el mundo y el orden social, al menos, el orden social propuesto por la masonería y que es, al fin y al cabo, el ilustrado, el de la modernidad y el occidental. No podemos estar más de acuerdo con las conclusiones de Jessica Harland-Jacobs ${ }^{86}$ : La masonería contribuyó de forma significativa a la historia de la globalización. Es un muestrario excelente, como hemos podido comprobar en estas páginas, para estudiar la intersección entre lo global y lo local, para comprender los procesos transculturales propiciados por la colonización, las tendencias político-sociales y económicas, así como multitud de factores que coordinaron a diferentes individuos en diferentes espacios y en diferentes contextos bajo preceptos comunes.

\footnotetext{
${ }^{86}$ Harland-Jacobs, “Fraternidad global: masonería, imperios y globalización”, 65-93.
} 


\section{Bibliografía}

Aguiar Bobet, Valeria. "La cultura de la tolerancia en el Marruecos de la II República: el VIII Centenario de Maimónides" En La masonería hispano-lusa y americana, De los Absolutismos a las Democracias (1815-2015). Editado por José Miguel Delgado Idarreta e Yván Pozuelo. Zaragoza: CEHME, Universidad de Zaragoza y Universidad de Oviedo, 2017.

Amador Martínez. Militares y marinos destacados. Héroes y Protagonistas del Ejército. Ciudad de México: Secretaría de la Defensa Nacional, Dirección General de Comunicación Social, Sección de Difusión Interna, 2011.

Betes, Antonio G. "Cincuentenario del vuelo Sevilla-Camaguey". Aeroplano, Revista de Historia Aeronáutica 1 (junio 1983). http://www.ejercitodelaire.mde.es/stweb/ea/ficheros/pdf/34BBB165546B71ADC12 574DD00226847.pdf

Harland-Jacobs, Jéssica. "Fraternidad global: masonería, imperios y globalización”. En 300 años. Masonerías y masones. Tomo V. Cosmopolitismos. Editado por Ricardo Martínez Esquivel, Yván Pozuelo y Rogelio Aragón. Ciudad de México: Palabra de Clío, 2018.

Imízcoz Beunza, José María y Arroyo Ruiz, Lara. "Redes sociales y correspondencia epistolar. Del análisis cualitativo de las relaciones personales a la reconstrucción de redes egocentradas". REDES, Revista hispana para el análisis de redes sociales 21 , no. 2 (diciembre 2011): 98-138. http://revistes.uab.cat/redes/article/view/419

López García, Bernabé. “Los españoles en Tánger”. AWRAQ 5-6 (2012): 1-45.

Madariaga, $\mathrm{M}^{\mathrm{a}}$ Rosa de. "La II República en el protectorado: reformes y contrarreformas administratives y burocráticas”. AWRAQ 5-6 (2012): 97-115.

Martín, Luis P. “El Internacionalismo Masónico. Génesis y conflictos (1895-1920)”. En La Masonería española entre Europa y América. Coordinado por José Antonio Ferrer Benimeli. Zaragoza: CEHME, 2004.

Martín, Luis P. "La Asociación Masónica Internacional (1921-1940) o la utopía pacifista”. En La masonería en la España del siglo XX. Coordinado por José Antonio Ferrer Benimeli. Ciudad Real: Universidad Castilla La Mancha, CEHME, Cortes Castilla La Mancha, 1996.

Mateo Dieste, Josep Lluis. "Una hermandad en tensión. Ideología colonial, barreras e intersecciones hispano-marroquíes en el protectorado". AWRAQ 5-6 (2012): 79-96.

Moga Romero, Vicente. Al oriente de África. Melilla: UNED-Centro Asociado de Melilla, 2005.

Moga Romero, Vicente y Adoración Perpén Rueda. “Orígenes ideológicos de los talleres masónicos contemporáneos en Melilla: Militares y Masonería (1983-1927)”. En 
Masonería, revolución y reacción. Coordinado por José Antonio Ferrer Benimeli. Alicante: CEHME, 1990.

Mollés, Dévrig. "Triangle atlàntiques et triangle latin: l'Amérique latine et le systèmemonde maçonnique (1717-1921)". REHMLAC 1, no. 5 (mayo-noviembre 2013): 188-196. https://revistas.ucr.ac.cr/index.php/rehmlac/article/view/10367/9754

Mollés, Dévrig. "Le système-monde maconnique à la veille de la Première Guerre mondiale: une analyse archéologique". REHMLAC 6, no. 2 (diciembre 2014-abril 2015): 12-32. https://revistas.ucr.ac.cr/index.php/rehmlac/article/view/18196/22736

Mollés, Dévrig. "Le "Triangle atlantique": émergence et expansion de la sphère maçonnique internationale". Nuevo Mundo Mundos Nuevos (noviembre 2014). https://nuevomundo.revues.org/67498?lang=es\#text

Mollés, Dévrig. "L' histoire globale et la question maçonnique: éléments pour une analyse". REHMLAC 6, no. 1 (mayo-diciembre 2014): 1-32. http://revistas.ucr.ac.cr/index.php/REHMLAC/article/view/15225

Paz Sánchez, Manuel de. "España, Cuba y Marruecos: masonería, identidades y construcción nacional”. Anuario de Estudio Atlánticos 55 (2009): 273-310.

Paz Sánchez, Manuel de. La masonería y la pérdida de las colonias. Santa Cruz De Tenerife: Idea, 2006.

Pedrique, Luisa. "La diáspora sefardí en el Nuevo Mundo". Presente y Pasado. Revista de Historia 8 (2003): 203-224.

Pozuelo, Yván. "Las relaciones masónicas entre Asturias e Hispanoamérica en los siglos XIX y XX. Estado de la cuestión". REHMLAC 1, no. 1 (mayo-noviembre 2009): 262-281. https://revistas.ucr.ac.cr/index.php/rehmlac/article/view/6867/6554

Pozuelo, Yván. "Relaciones y opiniones oficiales de las masonerías españolas sobre Iberoamérica durante la II República (1931-1935)". REHMLAC 2, no. 2 (diciembre 2010-abril 2011):

134-135. http://revistas.ucr.ac.cr/index.php/REHMLAC/article/view/6600

Roldán Rabadán, M.T. "El Gran Oriente Español. Relaciones Exteriores. Siglos XIX y XX”. En Masonería, revolución y reacción. Coordinado por José Antonio Ferrer Benimeli. Zaragoza: CEHME, 2004.

Sánchez Ferré, Pere. "La GLE, un ejemplo de vocación política en la masonería peninsular (1886-1939)”. En Masonería, revolución y reacción. Coordinado por José Antonio Ferrer Benimeli. Zaragoza: CEHME, 2004.

Villa García, Roberto. "La Logia Hispano Americana no. 379 de Madrid (1915-1935)”. En La Masonería en Madrid y en España del siglo XVIII al XXI. Coordinado por José Antonio Ferrer Benimeli. Zaragoza: CEHME, 2004. 